\title{
The Woodwardian Synthesis of Erythromycin A
}

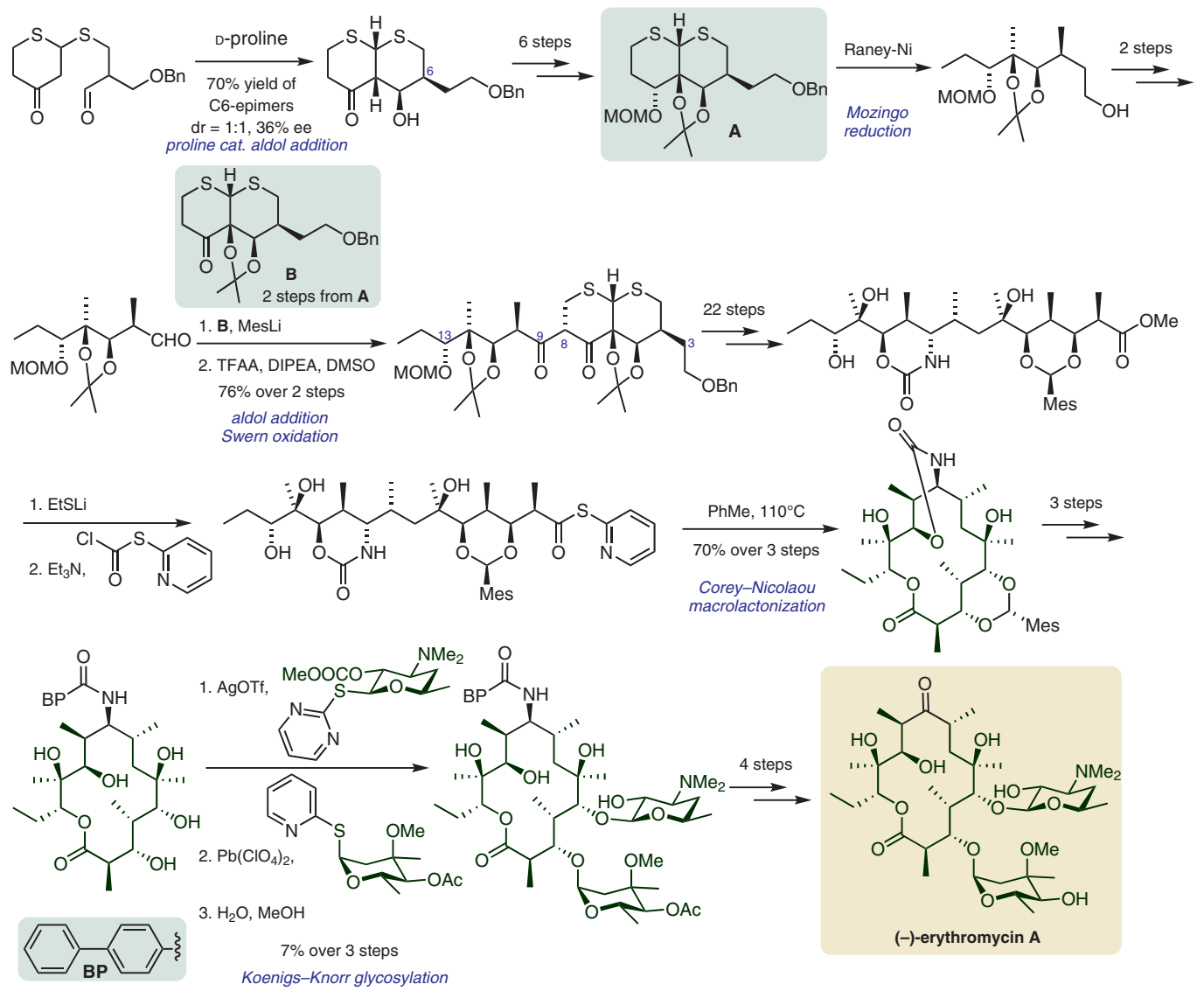

Category

Chemistry in

Medicine and

Biology

Key words

antibiotics

dithiadecaline

Mozingo reduction

Corey-Nicolaou macrolactonization

Koenigs-Knorr glycosylation
Significance: Erythromycin A and its various macrolide analogues have been identified as potent broad-spectrum antibiotics that disrupt protein synthesis by blocking the bacterial ribosome. This promising therapeutic value, along with the structural challenge of the molecule, quickly attracted the attention of the synthesis community after its isolation in 1949. In 1956, R. B. Woodward stated that 'Erythromycin, with all of our advantages, looks at present quite hopelessly complicated, particularly in view of its plethora of asymmetric centers.' 25 years later his research group disclosed the first complete synthesis of erythromycin A, just about two years after Woodward had passed away.
Comment: One of the key insights of Woodward was identifying the similarity between the C3 to C8- and the C9 to C13-fragments and using dithiadecaline $\mathbf{A}$ as a common precursor. The rigidity of the ring system allowed for the stereoselectivity of multiple operations before it was desulfurized under Raney-nickel conditions. Interestingly, macrolactonization required the conformational bias of a cyclic acetal and carbamate. Glycosylation of the fully functionalized macrolactone with D-desosamine and L-cladinose occurred site- and stereoselectively. 